\title{
RU486, a glucocorticoid receptor antagonist, induces apoptosis in U937 human lymphoma cells through reduction in mitochondrial membrane potential and activation of p38 MAPK
}

\author{
JI HOON JANG ${ }^{1}$, SEON MIN WOO ${ }^{1}$, HEE JUNG UM ${ }^{1}$, EUN JUNG PARK ${ }^{1}$, KYOUNG-JIN MIN ${ }^{1}$, \\ TAE-JIN LEE ${ }^{2}$, SANG HYUN KIM ${ }^{3}$, YUNG HYUN CHOI ${ }^{4}$ and TAEG KYU KWON ${ }^{1}$ \\ ${ }^{1}$ Department of Immunology, School of Medicine, Keimyung University, Dalseo-Gu, Daegu; ${ }^{2}$ Department of Anatomy,
College of Medicine, Yeungnam University, Daegu; ${ }^{3}$ Department of Pharmacology, School of Medicine,
Kyungpook National University, Daegu; ${ }^{4}$ Department of Biochemistry, College of Oriental Medicine,
Dong-Eui University, Busan, Republic of Korea
}

Received February 11, 2013; Accepted April 4, 2013

DOI: $10.3892 /$ or.2013.2432

\begin{abstract}
RU486 (mifepristone) exerts an anticancer effect on cancer cells via induction of apoptosis. However, the molecular mechanisms are not fully understood. Here, we investigated the effect of RU486 on the apoptosis of U937 human leukemia cells. RU486 markedly increased apoptosis in U937 cells as well as in MDA231 human breast carcinoma, A549 human lung adenocarcinoma epithelial and HCT116 human colorectal carcinoma cells. RU486 increased dose-dependent release of mitochondrial cytochrome $c$, and reduced the mitochondrial membrane potential (MMP, $\Delta \psi \mathrm{m}$ ) in RU486-treated U937 cells. We also found that overexpression of Bcl-2 completely blocked RU486-mediated apoptosis. However, reactive oxygen species signaling had no effect on RU486-induced apoptosis. RU486 increased the phosphorylation of p38 MAPK and JNK, but p38 MAPK only was associated with RU486-mediated apoptosis. Taken together, RU486 induces apoptosis through reduction in the mitochondrial membrane potential and activation of p38 MAPK in U937 human leukemia cells.
\end{abstract}

\section{Introduction}

RU486 (mifepristone) is a derivative of the progestin norethindrone, and acts as a progesterone receptor antagonist $(1,2)$ or glucocorticoid receptor antagonist $(3,4)$. RU486 has potential antitumor antineoplastic effects, and thus has been used for the treatment of several types of cancers. In breast cancer, RU486 was found to inhibit cell growth in a progesterone

Correspondence to: Professor Taeg Kyu Kwon, Department of Immunology, School of Medicine, Keimyung University, 2800 Dalgubeoldaero, Dalseo-Gu, Daegu 704-701, Republic of Korea E-mail: kwontk@dsmc.or.kr

Key words: RU486, apoptosis, caspase-3, p38 MAPK, mitochondrial membrane potential receptor-dependent manner (5). RU486 also induced cell growth inhibition in human ovarian epithelial carcinoma (6). Furthermore, in vivo, RU486 reduced tumor growth in human meningioma-implanted athymic nude mice (7). Although the effect of RU486 on cancer cells has been studied, the apoptosis-induced mechanism of RU486 remains unclear in human leukemia cells.

Proteins of the Bcl-2 family consist of pro-apoptotic (Bax and Bak) and anti-apoptotic members (Bcl-2 and Bcl-xL). The balance between the pro-apoptotic Bcl-2 family and the anti-apoptotic Bcl-2 family regulates mitochondrial functions. When the pro-apoptotic Bcl-2 family is enhanced or the anti-apoptotic Bcl-2 family is reduced, the permeability of the mitochondrial membrane is increased, and then apoptogenic factors, such as cytochome $c$, second mitochondria-derived activator of caspase (Smac)/direct inhibitor of apoptosis-binding protein with low pI (DIABLO), Omi/Htra2, endonuclease $\mathrm{G}$, and apoptosis-inducing factor are released $(8,9)$. Smac/DIABLO and Omi/Htra2 facilitate caspase activation, and endonuclease $\mathrm{G}$ and AIF induce DNA fragmentation. Released apoptotic proteins activate caspase signaling and initiate caspase-mediated DNA fragmentation and cell death signaling. Therefore, the $\mathrm{Bcl}-2$ family is important for the modulation of mitochondrial-mediated apoptosis.

In the present study, we examined the mechanism of RU486-induced apoptosis in U937 human leukemia cells. We found that reduction in mitochondrial membrane potential and activation of p38 MAPK are associated with RU486-induced apoptosis.

\section{Materials and methods}

Cells and materials. U937, A549, MDA231 and HCT116 cells were obtained from the American Type Culture Collection (ATCC, Rockville, MD, USA). The culture medium used throughout these experiments was RPMI-1640 (U937, A549, and HCT116) or DMEM (MDA231), containing 10\% fetal bovine serum (FBS), $20 \mathrm{mM}$ HEPES buffer and $100 \mu \mathrm{g} / \mathrm{ml}$ gentamicin. Bcl-2-overexpressing U937 cells were gener- 
ated using a pMAX vector containing the human $B c l-2$ gene (provided by Dr Rakesh Srivastava, NIH/NIA). U937 cells $(400 \mu \mathrm{l})$ in RPMI-1640 $\left(20 \times 10^{6}\right.$ cells $\left./ \mathrm{ml}\right)$ were transfected by pre-incubation with $15 \mu \mathrm{g}$ of the Bcl-2 plasmid for $10 \mathrm{~min}$ at room temperature and then electroporating at $500 \mathrm{~V}, 700 \mu \mathrm{F}$. The sample was immediately placed on ice for $10 \mathrm{~min}$ and then $10 \mathrm{ml}$ complete medium was added and the cells were incubated at $37^{\circ} \mathrm{C}$ for $24 \mathrm{~h}$. The cells were selected in a medium containing $0.7 \mu \mathrm{g} / \mathrm{ml}$ geneticin (G418) for 4 weeks. Single-cell clones were obtained by limiting dilution and were subsequently analyzed for an increase in $\mathrm{Bcl}-2$ protein expression relative to the identically cloned empty vector control. Chemicals were purchased from Sigma-Aldrich (St. Louis, MO, USA). Anti-Bcl-2, anti-Bcl-xL, anti-Mcl-1, anti-XIAP, anti-cIAP1, anti-cIAP2, anti-cytochrome $c$, and anti-PARP antibodies were purchased from Santa Cruz Biotechnology, Inc. (Santa Cruz, CA, USA). Anti-c-FLIP(L) antibody was obtained from Alexis Corporation (San Diego, CA, USA). Anti-phospho-ERK, anti-phospho-JNK, antiJNK, anti-phospho-p38 MAPK and anti-p38 antibodies were purchased from Cell Signaling Technology (Beverly, MA, USA). Anti-ERK antibody was obtained from Transduction Laboratories (Lexington, KY, USA). Anti-Qps-2 antibody was purchased from Molecular Probes (Eugene, OR, USA). Antiactin antibody was obtained from Sigma-Aldrich.

Flow cytometric analysis. Cells were suspended in $100 \mu \mathrm{l}$ of phosphate-buffered saline (PBS), and $200 \mu \mathrm{l}$ of $95 \%$ ethanol was added during vortexing. Cells were incubated at $4{ }^{\circ} \mathrm{C}$ for $1 \mathrm{~h}$, washed with PBS and resuspended in $250 \mu \mathrm{l}$ of $1.12 \%$ sodium citrate buffer ( $\mathrm{pH} 8.4$ ) together with $12.5 \mu \mathrm{g}$ of RNase. Incubation was continued at $37^{\circ} \mathrm{C}$ for $30 \mathrm{~min}$. The cellular DNA was then stained by applying $250 \mu \mathrm{l}$ of propidium iodide $(50 \mu \mathrm{g} / \mathrm{ml})$ for $30 \mathrm{~min}$ at room temperature. The stained cells were analyzed by fluorescence-activated cell sorting on a FACScan flow cytometer for the relative DNA content based on red fluorescence.

Cell death assessment by DNA fragmentation assays. The cell death detection ELISAPLUS kit (Boehringer Mannheim, Indianapolis, IN, USA) was used for assessing apoptotic activity by detecting fragmented DNA within the nucleus in the RU486-treated cells. Briefly, each culture plate was centrifuged for $10 \mathrm{~min}$ at $200 \mathrm{x} \mathrm{g}$, the supernatant was removed, and the pellet was lysed for $30 \mathrm{~min}$. After centrifuging the plate again at $200 \mathrm{x}$ g for $10 \mathrm{~min}$, the collected supernatant containing cytoplasmic histone-associated DNA fragments was incubated with an immobilized anti-histone antibody, and the reaction products were determined by spectrophotometry. Finally, the absorbance at $405 \mathrm{~nm}$ and $490 \mathrm{~nm}$ (reference wavelength), upon incubating with a peroxidase substrate for $5 \mathrm{~min}$, was determined with a microplate reader. Signals in the wells containing the substrate only were subtracted as background.

DEVDase activity assay. After treatment, cells were lysed, and $20 \mu \mathrm{g}$ of cell lysates was incubated with $100 \mu \mathrm{l}$ reaction buffer (1\% NP-40, 20 mmol/1 Tris-HCl (pH 7.5), 137 mmol/1 $\mathrm{NaCl}, 10 \%$ glycerol) containing the caspase substrate (DEVDchromophore $p$-nitroanilide) at $5 \mu \mathrm{mol} / 1$. Lysates were incubated at $37^{\circ} \mathrm{C}$ for $2 \mathrm{~h}$. The absorbance at $405 \mathrm{~nm}$ was measured with a spectrophotometer.

Western blot analysis. Cellular lysates were prepared by suspending $1.2 \times 10^{6}$ cells in $100 \mu \mathrm{l}$ of lysis buffer $(137 \mathrm{mM}$ $\mathrm{NaCl}, 15 \mathrm{mM}$ EGTA, $0.1 \mathrm{mM}$ sodium orthovanadate, $15 \mathrm{mM}$ $\mathrm{MgCl}_{2}, 0.1 \%$ Triton X-100, $25 \mathrm{mM}$ MOPS, $100 \mu \mathrm{M}$ phenylmethylsulfonyl fluoride, and $20 \mu \mathrm{M}$ leupeptin, adjusted to $\mathrm{pH}$ 7.2). The cells were disrupted by sonication and extracted at $4^{\circ} \mathrm{C}$ for $30 \mathrm{~min}$. The proteins were electrotransferred to Immobilon-P membranes (Millipore Corp., USA). Detection of specific proteins was carried out with an ECL western blotting kit according to the manufacturer's instructions.

Analysis of cytochrome c release. U937 human leukemia cells $\left(1.2 \times 10^{6}\right.$ cells $\left./ \mathrm{ml}\right)$ were harvested, washed once with ice-cold PBS and gently lysed for $2 \mathrm{~min}$ in $80 \mu \mathrm{l}$ ice-cold lysis buffer [250 mM sucrose, $1 \mathrm{mM}$ EDTA, $20 \mathrm{mM}$ Tris- $\mathrm{HCl}$ (pH 7.2), $1 \mathrm{mM}$ DTT, $10 \mathrm{mM} \mathrm{KCl}, 1.5 \mathrm{mM} \mathrm{MgCl}, 5 \mu \mathrm{g} / \mathrm{ml}$ pepstatin A, $10 \mu \mathrm{g} / \mathrm{ml}$ leupeptin and $2 \mu \mathrm{g} / \mathrm{ml}$ aprotinin]. Lysates were centrifuged at $12,000 \mathrm{x} \mathrm{g}$ at $4{ }^{\circ} \mathrm{C}$ for $10 \mathrm{~min}$ to obtain the supernatants (cytosolic extracts free of mitochondria) and the pellets (fraction that contains mitochondria). The resulting cytosolic fractions were used for western blot analysis using an anti-cytochrome $c$ antibody.

Determination for the mitochondrial membrane potential by rhodamine 123. Rhodamine 123 (Molecular Probes, Inc., Eugene, OR, USA) uptake by mitochondria is directly proportional to its membrane potential. U937 cells subjected to a 4-h treatment were incubated with rhodamine $123(5 \mu \mathrm{M})$ for $30 \mathrm{~min}$ in the dark at $37^{\circ} \mathrm{C}$. The cells were harvested and suspended in PBS. The mitochondrial membrane potential was subsequently analyzed using a flow cytometer (BectonDickinson, Franklin Lakes, NJ, USA).

Statistical analysis. Data were analyzed with one-way ANOVA, followed by post hoc comparisons (Student-Newman-Keuls) using the Statistical Package for Social Sciences 8.0 (SPSS Inc., Chicago, IL, USA).

\section{Results}

Cellular features characteristic of apoptosis in U937 cells exposed to RU486. In order to investigate whether RU486 induces apoptosis, U937 cells were treated with various concentrations of RU486 for $12 \mathrm{~h}$. We first determined the apoptosis in U937 cells using flow cytometric analysis to detect hypodiploid cell populations. As shown in Fig. 1A, treatment of U937 cells with RU486 resulted in a markedly increased accumulation of sub-G1 phase cells in a dose-dependent manner. Next, we also investigated whether RU486 induces the apoptotic DNA fraction in U937 cells. As shown in Fig. 1B, increasing concentrations of RU486 induced the progressive accumulation of apoptotic DNA. Since cells undergoing apoptosis execute the death program by activating caspases and cleaving PARP (10), we next analyzed PARP cleavage. Exposure to RU486 induced a dose-dependent cleavage of PARP (Fig. 1C). These results suggest that RU486 induced apoptosis in the U937 human leukemia cells. In addition, RU486-induced apoptosis was 

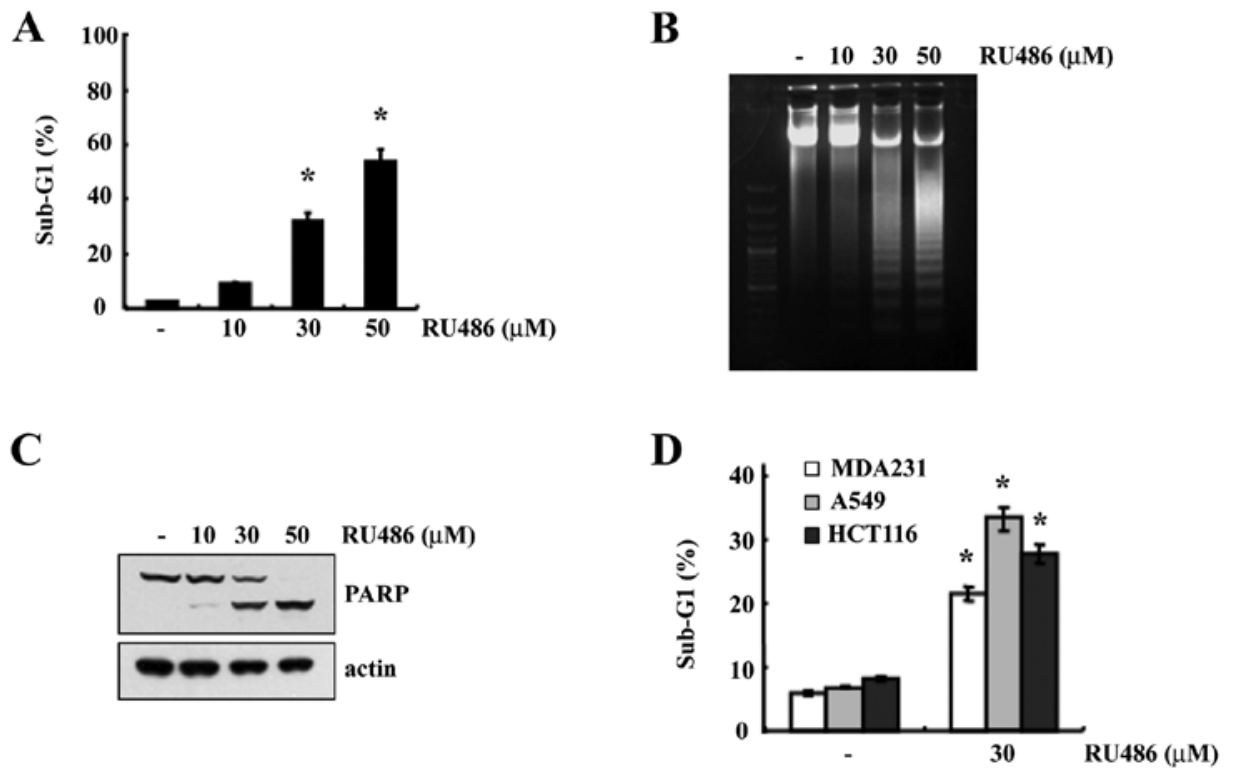

Figure 1. RU486 induces apoptosis in U937 human leukemic cells. (A-C) Cells were treated with the indicated concentrations of RU486 for $12 \mathrm{~h}$. (A) Apoptosis was analyzed by determining the sub-G1 cell fraction by FACS. (B) Fragmented DNA was extracted and analyzed on $2 \%$ agarose gel. (C) Equal amounts of cell lysates $(40 \mu \mathrm{g})$ were subjected to electrophoresis and analyzed by western blotting for PARP. Actin was used as a control for protein loading. (D) MDA231, A549 and HCT116 cells were treated with $30 \mu \mathrm{M}$ RU486 for $12 \mathrm{~h}$. Apoptosis was analyzed by determing the sub-G1 cell fraction by FACS. Values in A and D are expressed as mean \pm standard deviation (SD) of three independent experiments. ${ }^{*} \mathrm{P}<0.001$ compared to control. The data represent three independent experiments.
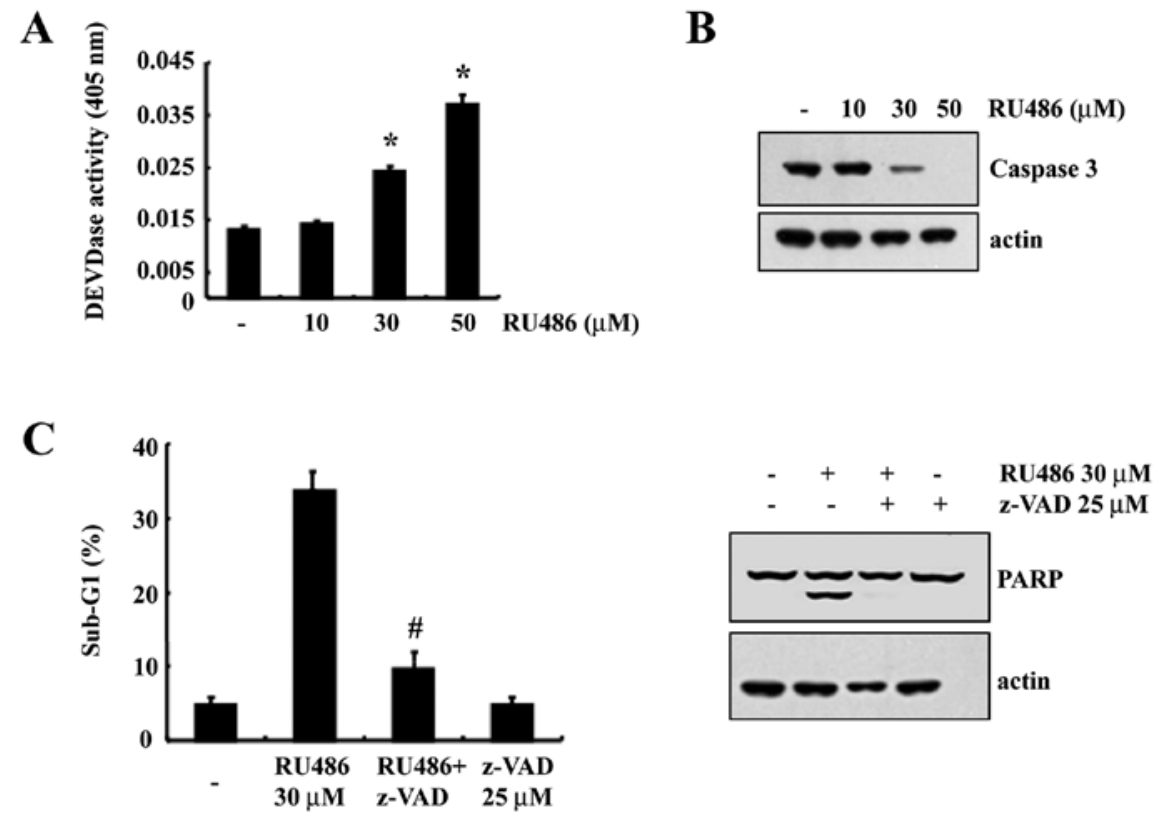

Figure 2. Caspase activation is associated with RU486-induced apoptosis. (A and B) U937 cells were treated with the indicated concentrations of RU486 for $12 \mathrm{~h}$. (A) Caspase activity was determined by colorimetric assays using caspase-3 DEVDase assay kits. (B) Equal amounts of cell lysates (40 $\mu \mathrm{g}$ ) were subjected to electrophoresis and analyzed by western blotting for caspase-3. Actin was used as a control for protein loading. (C) U937 cells were pretreated with $25 \mu \mathrm{M}$ z-VAD-fmk for $30 \mathrm{~min}$, and $30 \mu \mathrm{M}$ RU486 was added for $12 \mathrm{~h}$. Apoptosis was analyzed by determining the sub-G1 cell fraction by FACS (left panel). Equal amounts of cell lysates $(40 \mu \mathrm{g})$ were subjected to electrophoresis and analyzed by western blotting for PARP. Actin was used as a control for protein loading (right panel). Values in $\mathrm{A}$ and $\mathrm{C}$ are expressed as the means $\pm \mathrm{SD}$ of three independent experiments. ${ }^{~} \mathrm{P}<0.001$ compared to control. ${ }^{\#} \mathrm{P}<0.001$ compared to $30 \mu \mathrm{M}$ RU486. The data represent three independent experiments.

also observed in a variety of tumor cell types [breast carcinoma cells (MDA231), lung carcinoma cells (A549) and colon cancer cells (HCT116)], demonstrating that RU486-induced apoptosis is a common response in various types of cancer cells (Fig. 1D).
Inhibition of RU486-induced apoptosis by a caspase-3 inhibitor. We next analyzed whether treatment with RU486 results in the activation of caspases, a key executioner of apoptosis. Exposure of U937 cells to RU486 strongly stimulated caspase-3 activity in a dose-dependent manner (Fig. 2A). As 
A

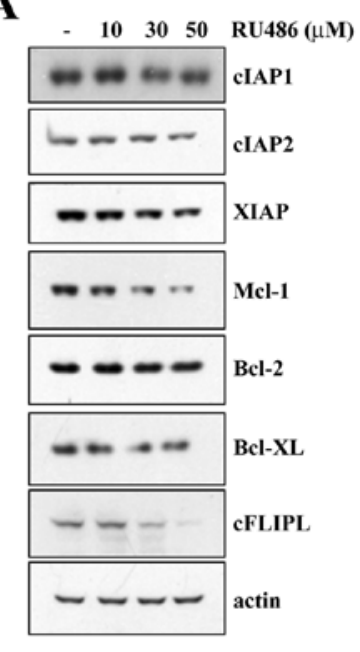

B

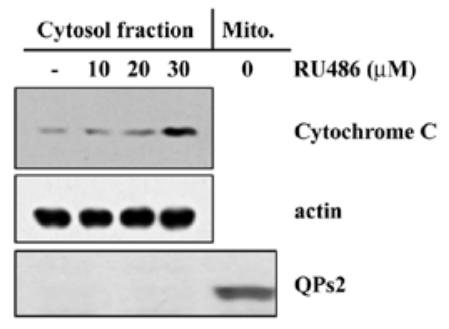

C

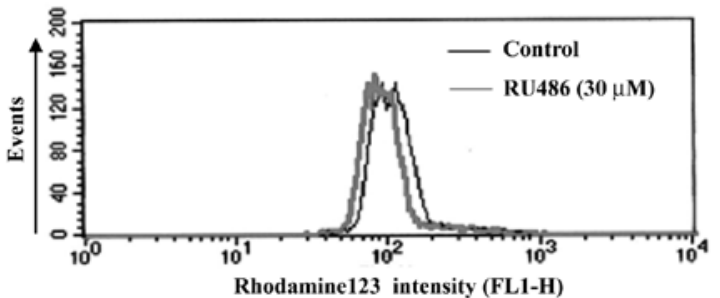

Figure 3. RU486 induces release of cytochrome $c$ into the cytoplasm. (A) U937 cells were treated with the indicated concentrations of RU486 for 12 h. Equal amounts of cell lysates $(40 \mu \mathrm{g})$ were subjected to electrophoresis and analyzed by western blotting for cIAP1, cIAP2, XIAP, Mcl-1, cFLIP(L), Bcl-2 and Bcl-xL. Actin was used as a control for protein loading. (B) U937 cells were treated with indicated concentrations of RU486 for 4 h. Extracts of the cytosol fraction and mitochondria fraction (Mito.) were prepared as described in 'Materials and methods'. Equal amounts of cell lysates (40 $\mu \mathrm{g}$ ) were subjected to electrophoresis and analyzed by western blotting for cytochrome $c$. Actin was used as a control for protein loading. To show that there was no mitochondrial contamination in the cytosol fraction, we carried out western blot analysis using an antibody against QPs 2 that is expressed in mitochondria. The mitochondrial fraction derived from the non-treated cells was used as a positive control. (C) U937 cells were treated with $30 \mu \mathrm{M}$ RU486 for 4 h. The mitochondrial membrane potential was measured as described in 'Materials and methods'. The data represent three independent experiments.

shown in Fig. 2B, western blot analysis showed that RU486 concentration-dependently induced a marked change in the cleavage of caspase-3. In order to confirm that the activation of caspase-3 is a key step in the RU486-induced apoptotic pathway, U937 cells were pretreated with z-VAD-fmk $(25 \mu \mathrm{M})$, a cell-permeable pan-caspase inhibitor, followed by treatment with $30 \mu \mathrm{M}$ RU486 for $12 \mathrm{~h}$. As shown in Fig. 2C, RU486induced apoptosis was significantly prevented by pretreatment with the potent inhibitor of caspases, z-VAD-fmk, as determined by FACS analysis. We also found that $\mathrm{z}$-VAD-fmk prevented caspase-related events such as cleavage of PARP (Fig. 2C). These results suggest that RU486-induced cell death is associated with caspase- 3 activation.

RU486 induces the downregulation of anti-apoptotic proteins and cytochrome c release. To investigate the underlying mechanisms involved in RU486-induced apoptosis, we analyzed the changes in the expression levels of various anti-apoptotic proteins. As shown in Fig. 3A, protein levels of Bcl-2, Bcl-xL, cIAP1 and cIAP2 were not altered in response to RU486 treatment. However, protein levels of Mcl-1, cFLIP(L) and XIAP were markedly reduced in U937 cells following treatment at the indicated concentrations of RU486 in a dose-dependent manner. Accumulating evidence suggests that mitochondria play an essential role in apoptosis by releasing apoptogenic effectors such as cytochrome $c$. When we performed western blot analysis using cytosolic fractions to examine the release of mitochondrial cytochrome $c$ in RU486-treated U937 cells, RU486 treatment markedly induced a dose-dependent release of cytochrome $c$ into the cytoplasm (Fig. 3B). In addition, the role of mitochondria in RU486-induced apoptosis of U937 cells was further investigated by examining the effect of RU486 on mitochondrial membrane potential (MMP, $\Delta \psi \mathrm{m}$ ). Exposure of U937 cells to $30 \mu \mathrm{M}$ RU486 for $4 \mathrm{~h}$ led to a significant reduction in the MMP level (Fig. 3C).

Effect of ectopic expression of Bcl-2 and antioxidant on RU486-induced apoptosis. In order to evaluate the functional role played by $\mathrm{Bcl}-2$ in preventing RU486-induced apoptosis, cells stably overexpressing Bcl-2 were established. As shown in Fig. 4A, treatment of U937/Vector cells with $30 \mu \mathrm{M}$ RU486 for $12 \mathrm{~h}$ resulted in a markedly increased accumulation of cells in the sub-G1 phase. In contrast, the accumulation of cells in the sub-G1 phase induced by RU486 was inhibited by Bcl-2 overexpression. Subsequent western blot analysis demonstrated that the proteolytic cleavage of PARP in U937/ Vector cells was more prominent than that in the U937/Bcl-2 cells when exposed to RU486 (Fig. 4A). Taken together, these results indicate that ectopic expression of $\mathrm{Bcl}-2$ inhibits RU486-induced apoptosis.

Since oxidative stress-mediated cellular changes are induced in cells exposed to cytotoxic drugs and ROS is known to be a mediator of caspase-dependent cell death (11-13), we investigated whether ROS generation induced by RU486 is directly associated with the induction of apoptosis. However, pretreatment with $\mathrm{N}$-acetylcysteine (NAC) did not prevent RU486-induced increase in the sub-G1 cell population and cleavage of PARP (Fig. 4B). These data indicate that ROS generation is not critical for the induction of apoptosis by RU486.

p38 MAPK pathways play important roles in RU486-induced apoptosis. We investigated the effect of RU486 treatment on the expression and activity of MAPKs in order to determine whether this signaling pathway is involved in mediating the observed apoptotic response. As shown in Fig. 5A, RU486 

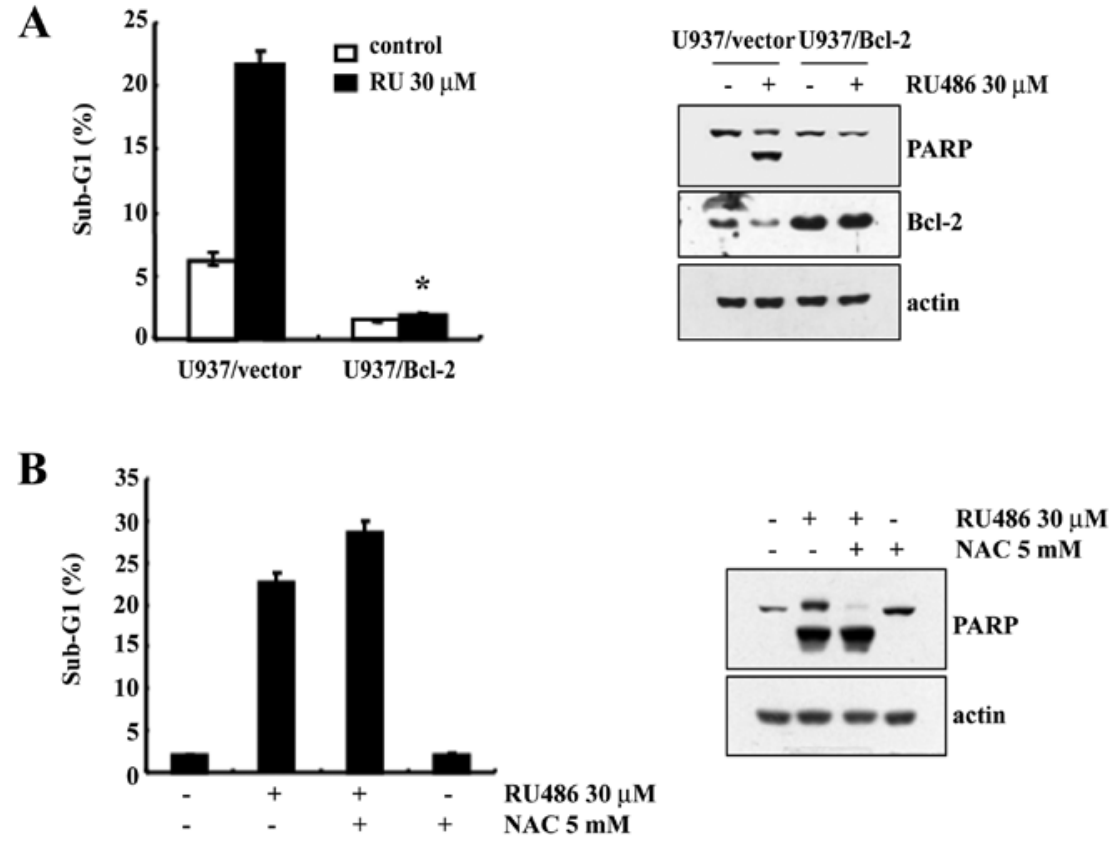

Figure 4. Ectopic expression of Bcl-2 reduces RU486-induced apoptosis. (A and B) U937 cells were stimulated with $30 \mu \mathrm{M}$ RU486 (RU) for $12 \mathrm{~h}$. (A) Apoptosis was analyzed by determining the sub-G1 cell fraction by FACS. Equal amounts of cell lysates $(40 \mu \mathrm{g})$ were subjected to electrophoresis and analyzed by western blotting for PARP and Bcl-2. Actin was used as a control for protein loading. (B) U937/vector and U937/Bcl-2 cells were pretreated with $5 \mathrm{mM} \mathrm{NAC}$ for $30 \mathrm{~min}$, and then stimulated with $30 \mu \mathrm{M}$ RU486 for $12 \mathrm{~h}$. Apoptosis was analyzed by determining the sub-G1 cell fraction by FACS. Equal amounts of cell lysates $(40 \mu \mathrm{g})$ were subjected to electrophoresis and analyzed by western blotting for PARP. Actin was used as a control for protein loading. Values in $\mathrm{A}$ and $\mathrm{B}$ (left panels) are expressed as means $\pm \mathrm{SD}$ of three independent experiments. " $\mathrm{P}<0.001$ compared to RU486-treated U937/Vec. The data represent three independent experiments.
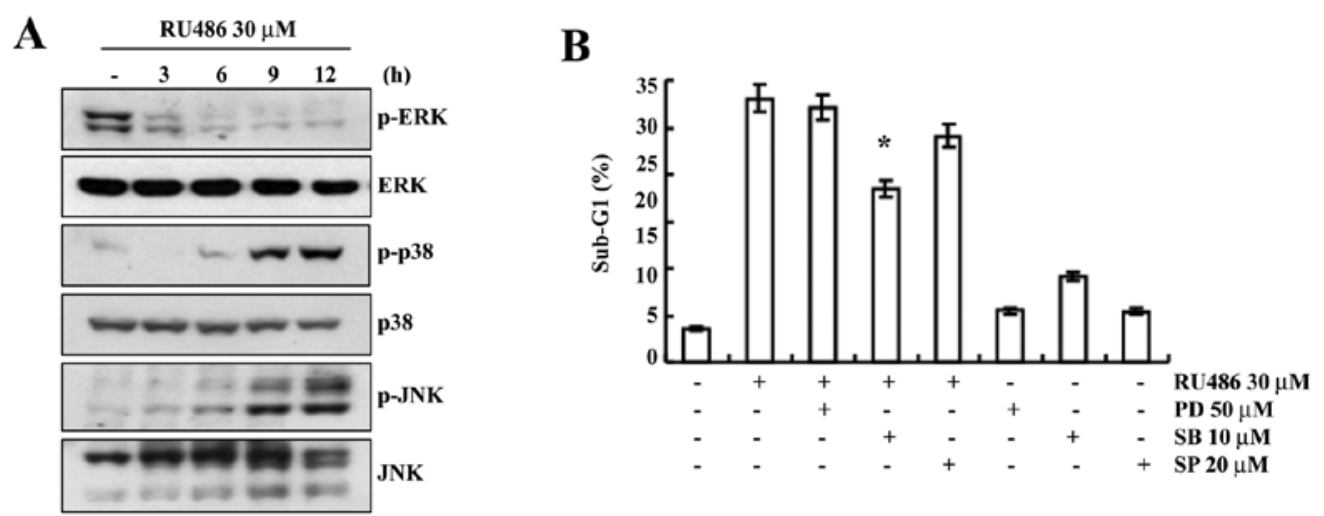

Figure 5. Activation of p38 MAPK is involved in RU486-induced apoptosis. (A) U937 cells were treated with $30 \mu$ M RU486 for the indicated time periods. Equal amounts of cell lysates $(40 \mu \mathrm{g})$ were subjected to electrophoresis and analyzed by western blotting for phospho (p)-ERK, ERK, p-p38 MAPK, p38 MAPK, p-JNK, and JNK. (B) U937 cells were pretreated with PD98059 (PD), SB203580 (SB) and SP600125 (SP) for 30 min, and then stimulated with $30 \mu \mathrm{M}$ RU486 for $12 \mathrm{~h}$. Apoptosis was analyzed by determining the sub-G1 cell fraction by FACS. Values in B are expressed as means \pm SD of three independent experiments. ${ }^{*} \mathrm{P}<0.001$ compared to RU486. The data represent three independent experiments.

treatment induced a decrease in the phosphorylated ERK levels in a time-dependent manner. However, the phosphorylation of p38 MAPK and JNK gradually increased after RU486 treatment. We then evaluated the possible roles of MAPKs in RU486 treatment-induced apoptosis. As shown in Fig. 5B, pretreatment with SB203580 (a specific inhibitor of p38 MAPK) decreased the sub-G1 phase cell population (17.3\%) when compared with the sub-G1 phase cell population following RU486 treatment (28.8\%), while treatment of SP600125 (a potent inhibitor of JNK) and PD98059 (a potent inhibitor of ERK) did not significantly decrease the number of cells with sub-G1 DNA content. These results indicate that the activation of the p38 MAPK pathway plays an important role in regulating RU486-induced apoptosis in U937 cells.

Taken together, our results demonstrated that RU486 induced apoptosis through reduction in mitochondrial membrane potential and activation of p38 MAPK in U937 human leukemia cells.

\section{Discussion}

RU486 is an anti-progestin, which was primarily used as an emergency contraceptive or abortion-inducing drug (14). RU486 was also found to demonstrate promising results in 
cancer therapy. However, it was unclear whether the mechanism of RU486 involves apoptosis of cancer cells. In this study, we tested whether RU486 has potential for the treatment of human leukemia and examined the mechanisms of RU486induced apoptosis in human leukemia cells. We observed the following. i) RU486 activated the caspase-dependent apoptotic pathway in a dose-dependent manner in U937 cells, which was significantly prevented by pretreatment with a pan-caspase inhibitor z-VAD-fmk (Fig. 2). ii) RU486-induced apoptosis was closely correlated with reduction in mitochondrial membrane potential (Fig. 3). iii) p38 MAPK inhibition by SB203580 (a specific inhibitor of p38 MAPK) effectively inhibited the cell death induced by RU486, demonstrating its critical role in this event (Fig. 5).

A previous report demonstrated that RU486 activity was partially due to promotion of cellular apoptosis through increased $\mathrm{NF}-\kappa \mathrm{B}$ binding resulting in overexpression of Bax and downregulation of Bcl-2 in a human endometrial epithelial cell line EM42 (15). Furthermore, in our previous study, RU486 sensitized TRAIL-mediated apoptosis through downregulation of $\mathrm{Bcl}-2$ in human renal carcinoma Caki cells (16). As shown in Fig. 4, ectopic expression of Bcl-2 significantly attenuated RU486-induced apoptosis and PARP cleavage in U937 cells. Since Bcl-2 inhibits members of the caspase family (17), ectopic expression of Bcl-2 inhibited RU486mediated apoptosis in leukemia U937 cells (Fig. 4A).

Mitogen-activated protein kinases (MAPKs) are serine/ threonine kinases and induce the phosphorylation of multiple substrates, which results in modulation of cellular proliferation, motility and cell death (18-21). MAPKs mainly consist of three family members (ERK, p38 MAPK and JNK). Although the function of each MAPK is dependent on cell type, stimuli, and duration of stimuli, ERK commonly has been known as an anti-apoptotic signal $(22,23)$. Activation of the ERK signaling pathway is involved in induction of cellular proliferation, differentiation and migration (24-26). In contrast, p38 MAPK and JNK are associated with apoptotic signaling (27). For examples, multiple stresses such as DNA damage, UV irradiation, and oxidative stress activate p38 MAPK and/or JNK, thus induce apoptosis (28-31). While RU486 activated p38 MAPK and JNK in a time-dependent manner (Fig. 5A), phosphorylation of ERK decreased in the RU486-treated cells. Among MAPKs, p38 MAPK was solely involved in RU486-induced apoptosis (Fig. 5B).

In conclusion, the results of our studies, for the first time, provide mechanistic evidence that RU486 induces apoptosis by loss of MMP, p38 MAPK activation and caspase activation. The apoptosis-inducing ability of RU486 makes it a potentially effective, preventive and/or therapeutic agent against leukemia. However, additional in vivo studies are needed to establish the role of RU486 as a chemopreventive and/or therapeutic agent for cancer.

\section{References}

1. Herrmann W, Wyss R, Riondel A, et al: The effects of an antiprogesterone steroid in women: interruption of the menstrual cycle and of early pregnancy. CR Seances Acad Sci III 294: 933-938, 1982 (in French).

2. Robbins A and Spitz IM: Mifepristone: clinical pharmacology. Clin Obstet Gynecol 39: 436-450, 1996.
3. Gagne D, Pons M and Philibert D: RU 38486: a potent antiglucocorticoid in vitro and in vivo. J Steroid Biochem 23: 247-251, 1985.

4. Jung-Testas I and Baulieu EE: Inhibition of glucocorticosteroid action in cultured L-929 mouse fibroblasts by RU 486, a new anti-glucocorticosteroid of high affinity for the glucocorticosteroid receptor. Exp Cell Res 147: 177-182, 1983.

5. Bardon S, Vignon F, Chalbos D and Rochefort H: RU486, a progestin and glucocorticoid antagonist, inhibits the growth of breast cancer cells via the progesterone receptor. J Clin Endocrinol Metab 60: 692-697, 1985.

6. Rose FV and Barnea ER: Response of human ovarian carcinoma cell lines to antiprogestin mifepristone. Oncogene 12: 999-1003, 1996.

7. Olson JJ, Beck DW, Schlechte JA and Loh PM: Effect of the antiprogesterone RU-38486 on meningioma implanted into nude mice. J Neurosurg 66: 584-587, 1987.

8. Cheng EH, Wei MC, Weiler S, et al: BCL-2, BCL-X(L) sequester BH3 domain-only molecules preventing BAX- and BAK-mediated mitochondrial apoptosis. Mol Cell 8: 705-711, 2001.

9. Ruffolo SC and Shore GC: BCL-2 selectively interacts with the BID-induced open conformer of BAK, inhibiting BAK autooligomerization. J Biol Chem 278: 25039-25045, 2003.

10. O'Brien MA, Moravec RA and Riss TL: Poly (ADP-ribose) polymerase cleavage monitored in situ in apoptotic cells. Biotechniques 30: 886-891, 2001.

11. Wen J, You KR, Lee SY, Song CH and Kim DG: Oxidative stress-mediated apoptosis. The anticancer effect of the sesquiterpene lactone parthenolide. J Biol Chem 277: 38954-38964, 2002.

12. Sheng-Tanner X, Bump EA and Hedley DW: An oxidative stress-mediated death pathway in irradiated human leukemia cells mapped using multilaser flow cytometry. Radiat Res 150: 636-647, 1998.

13. Fleury C, Mignotte B and Vayssière JL: Mitochondrial reactive oxygen species in cell death signaling. Biochimie 84: 131-141, 2002.

14. Mahajan DK and London SN: Mifepristone (RU486): a review. Fertil Steril 68: 967-976, 1997.

15. Han S and Sidell N: RU486-induced growth inhibition of human endometrial cells involves the nuclear factor-kappa B signaling pathway. J Clin Endocrinol Metab 88: 713-719, 2003.

16. Min KJ, Jang JH, Lee JT, Choi KS and Kwon TK: Glucocorticoid receptor antagonist sensitizes TRAIL-induced apoptosis in renal carcinoma cells through up-regulation of DR5 and downregulation of c-FLIP(L) and Bcl-2. J Mol Med (Berl) 90: 309-319, 2012.

17. Cory S and Adams JM: The Bcl-2 family: regulators of the cellular life-or-death switch. Nat Rev Cancer 2: 647-656, 2002.

18. Choudhury GG, Karamitsos C, Hernandez J, Gentilini A, Bardgette $\mathrm{J}$ and Abboud HE: PI-3-kinase and MAPK regulate mesangial cell proliferation and migration in response to PDGF. Am J Physiol 273: F931-F938, 1997.

19. Seger R and Krebs EG: The MAPK signaling cascade. FASEB J 9: 726-735, 1995.

20. Xi XP, Graf K, Goetze S, Fleck E, Hsueh WA and Law RE: Central role of the MAPK pathway in ang II-mediated DNA synthesis and migration in rat vascular smooth muscle cells. Arterioscler Thromb Vasc Biol 19: 73-82, 1999.

21. Bonni A, Brunet A, West AE, Datta SR, Takasu MA and Greenberg ME: Cell survival promoted by the Ras-MAPK signaling pathway by transcription-dependent and -independent mechanisms. Science 286: 1358-1362, 1999.

22. Kitagawa D, Tanemura S, Ohata S, et al: Activation of extracellular signal-regulated kinase by ultraviolet is mediated through Src-dependent epidermal growth factor receptor phosphorylation. Its implication in an anti-apoptotic function. J Biol Chem 277: 366-371, 2002.

23. Klein JB, Buridi A, Coxon PY, et al: Role of extracellular signal-regulated kinase and phosphatidylinositol-3 kinase in chemoattractant and LPS delay of constitutive neutrophil apoptosis. Cell Signal 13: 335-343, 2001.

24. Whelchel A, Evans J and Posada J: Inhibition of ERK activation attenuates endothelin-stimulated airway smooth muscle cell proliferation. Am J Respir Cell Mol Biol 16: 589-596, 1997.

25. Qui MS and Green SH: PC12 cell neuronal differentiation is associated with prolonged p21ras activity and consequent prolonged ERK activity. Neuron 9: 705-717, 1992. 
26. Graf K, Xi XP, Yang D, Fleck E, Hsueh WA and Law RE: Mitogen-activated protein kinase activation is involved in platelet-derived growth factor-directed migration by vascular smooth muscle cells. Hypertension 29: 334-339, 1997.

27. Xia Z, Dickens M, Raingeaud J, Davis RJ and Greenberg ME: Opposing effects of ERK and JNK-p38 MAP kinases on apoptosis. Science 270: 1326-1331, 1995.

28. Chen YR, Wang X, Templeton D, Davis RJ and Tan TH: The role of c-Jun N-terminal kinase (JNK) in apoptosis induced by ultraviolet $C$ and gamma radiation. Duration of JNK activation may determine cell death and proliferation. J Biol Chem 271: 31929-31936, 1996.
29. Turner NA, Xia F, Azhar G, Zhang X, Liu L and Wei JY: Oxidative stress induces DNA fragmentation and caspase activation via the c-Jun NH2-terminal kinase pathway in $\mathrm{H} 9 \mathrm{c} 2$ cardiac muscle cells. J Mol Cell Cardiol 30: 1789-1801, 1998.

30. Naderi J, Hung M and Pandey S: Oxidative stress-induced apoptosis in dividing fibroblasts involves activation of p38 MAP kinase and over-expression of Bax: resistance of quiescent cells to oxidative stress. Apoptosis 8: 91-100, 2003.

31. Luo Y, Umegaki H, Wang X, Abe R and Roth GS: Dopamine induces apoptosis through an oxidation-involved SAPK/JNK activation pathway. J Biol Chem 273: 3756-3764, 1998. 